\title{
ESTADO ACTUAL DE LA CARTOGRAFÍA DE LOS RIESGOS DE INUNDACIÓN Y SU APLICACIÓN EN LA ORDENACIÓN DEL TERRITORIO. EL CASO DE LA REGIÓN DE MURCIA
}

\author{
Alfredo Pérez Morales \\ Universidad de Murcia
}

\section{RESUMEN}

Los mapas de riesgos por inundaciones, han ido mejorando su precisión en los últimos años, sin embargo, la metodología no es homogénea ni atiende a las necesidades de los técnicos en ordenación del territorio. Es ahora cuando aparecen los primeros trabajos que verdaderamente pueden ser aplicados en las tareas planificación de territorios sensibles de ser afectados por las avenidas e inundaciones. Resulta interesante analizar la situación de dicha cartografía y el grado de aplicación de la misma en los procesos de asignación de usos del suelo.

Palabras clave: Cartografía, Riesgo, Inundación, Ordenación del Territorio.

\section{ABSTRACT}

The flood risk maps have been improving its accuracy in recent years, however, the methodology is not uniform or serving the needs of technical planning. It is now when the first work that truly can be applied to planning tasks sensitive areas to be affected by floods and floods. It is interesting to analyze the situation of the mapping and the degree of implementation of it in the process of assigning land use.

Key words: Cartography, Natural hazard, Flood, Land management.

Fecha de recepción: enero 2010.

Fecha de aceptación: febrero 2012. 
Los análisis de riesgos naturales requieren en la mayor parte de su desarrollo la expresión espacial de las áreas asociadas a una peligrosidad (tanto a distintas severidades como probabilidades de ocurrencia), así como la ubicación geográfica de los elementos en riesgo y sus vulnerabilidades. Por ello, la cartografía se ha convertido en una herramienta imprescindible en el análisis y evaluación de los riesgos naturales desde las etapas iniciales como fuente de información, pasando por el análisis como soporte de modelización, y finalizando con la edición de resultados como base de representación.

El mapa de riesgo representa la delimitación de zonas en las que existe la posibilidad de que una serie de sectores o elementos de la sociedad se vean afectados por una ocurrencia natural de tipo extremo. Por tanto, la zonificación del riesgo supone un proceso de integración de dos tipos de cartografía, el de peligrosidad, cuyo objetivo es la delimitación de zonas en función de la frecuencia e intensidad de ocurrencia de un determinado fenómeno natural, y el de vulnerabilidad y exposición, que viene a expresar la situación y permanencia temporal de los elementos en riesgo, fundamentalmente personas, bienes materiales y servicios, así como su fragilidad intrínseca ante la peligrosidad. Por último existe también la cartografía de gestión de emergencias, de fuerte carácter aplicado por cuanto que su finalidad es su utilización en los procesos operativos de intervención ante la ocurrencia de desastres naturales.

El papel de la cartografía es realmente importante en el caso del análisis del riesgo de inundación, ya que existen muy diferentes parámetros y variables del agente que pueden ser representados por su componente espacial (profundidad, velocidad, carga de sedimento, etc.). Además, esta expresión cartográfica de los niveles de riesgo facilita su integración con las medidas preventivas de carácter territorial, como es la ordenación y gestión de usos y permanencias en áreas de riesgo (Elízaga, 1983). A continuación se analizan cada una de las formas de expresión de este tipo de mapas.

\section{TIPOLOGÍA DE LOS MAPAS DE RIESGO DE INUNDACIÓN}

Los mapas de riesgo de inundación se pueden agrupar en cinco tipologías. En primer lugar, los que se podrían denominar «mapas de áreas inundables»; en segundo, los de peligrosidad; en tercero, los mapas de exposición; en cuarto, los mapas de vulnerabilidad a las inundaciones y, en quinto lugar, los que se podrían denominar «mapas de riesgo de daños por inundación» $\mathrm{o}$ «mapas de daños potenciales por inundación», de desarrollo más reciente, donde se contempla la variable vulnerabilidad (Pujadas, 1997).

Los primeros, los mapas de áreas inundables, los más comunes hasta el momento y hasta hace poco confundidos con los mapas de riesgo de daños potenciales por inundación (DÍEZ, 2002), se limitan a concretar el área potencialmente afectada por las inundaciones. En definitiva, se trata de determinar la ocurrencia o no de un suceso en un punto del territorio a parte de la aplicación de diferentes metodologías ampliamente utilizadas y complementarias como son la histórica, la geomorfológica y la hidrológica-hidráulica. El método histórico consiste, básicamente, en cartografiar las áreas inundables en episodios de inundación pasados. El método geomorfológico se fundamenta en el estudio de las formas del terreno provocadas por el paso del agua. Y, finalmente, el método hidrológico e hidráulico delimita las áreas potencialmente inundables a partir de los registros pluviométricos y mediciones de los caudales y del comportamiento físico del agua en función de la morfología del terreno; con él 
es posible, si se desea, calcular el periodo de retorno o, en otras palabras, la probabilidad de ocurrencia del fenómeno natural. Pero la limitación que presenta este tipo de cartografía es que, si bien describe con precisión el espacio inundable (información de muchísima utilidad), en cambio aporta una información más bien escasa sobre qué elementos se verán afectados y con qué intensidad.

Figura 1

METODOLOGÍAS PARA LA ELABORACIÓN DE MAPAS DE ÁREAS INUNDABLES

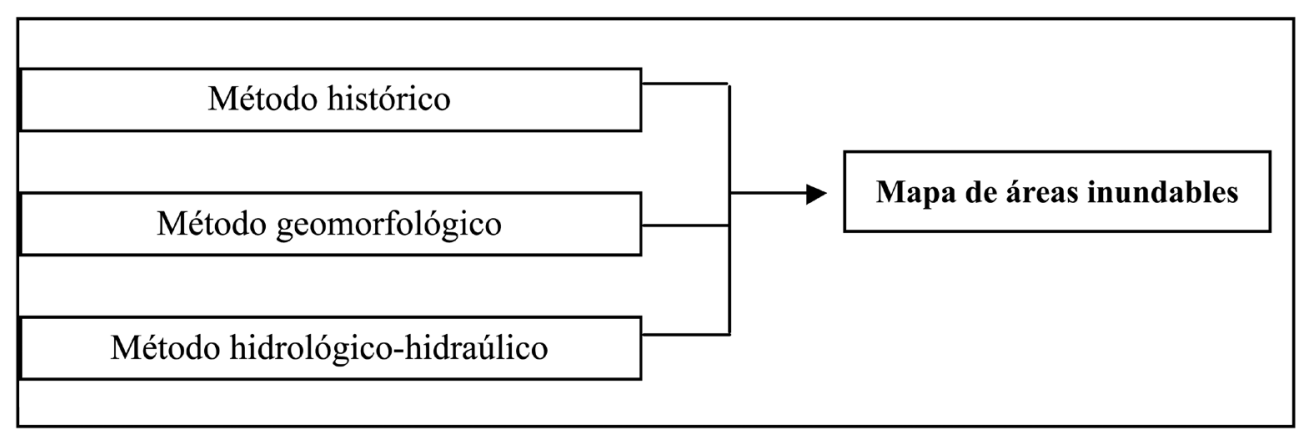

Fuente: Ribera, 2004.

En segundo lugar, los mapas de peligrosidad describen aquellas peculiaridades del suceso que lo pueden convertir en más o menos dañino. Por ejemplo, las profundidades y la velocidad del agua, la permanencia de la lámina de agua o la carga de transporte. La información de estos mapas puede ser sintetizada en los que podría denominar «mapa final de peligrosidad».

En tercer lugar, los mapas de exposición determinan la localización de los elementos expuestos en un periodo temporal concreto. Esta información es especialmente útil para conocer la situación de aquellos elementos que, por sus características de movilidad, pueden modificar su afectación respecto a un suceso determinado. La alta movilidad de las personas o de los vehículos, por ejemplo, obliga a confeccionar un mapa de exposición lo más detallado posible.

En cuarto lugar, los mapas de vulnerabilidad a las inundaciones describen aquellas características de los elementos a estudiar que incrementan o disminuyen el impacto de una inundación si ésta se llega a producir. Algunas de las variables a estudiar pueden ser las edades, el género, los ingresos económicos, el nivel de formación en el caso de los estudios de posibles afectaciones a la población o las características estructurales de las infraestructuras, las viviendas y las vías de comunicación si lo que se pretende es conocer el potencial impacto en estas construcciones. De la misma forma que en los dos primeros mapas mencionados, la información de estos otros dos puede ser sintetizada en lo que se podría denominar «mapa final de vulnerabilidad».

Finalmente, los mapas de riesgo de daños por inundación, en un sentido estricto y en coherencia con lo expuesto anteriormente, son los verdaderos mapas de riesgo, puesto que se muestran las inundaciones en relación con el impacto que éstas pueden llegar a producir 
en personas, bienes y actividades. Para su realización, se debe disponer de los cuatros mapas anteriores: los dos primeros (de áreas inundables y de peligrosidad), para localizar y caracterizar el suceso y que dan lugar al mapa final de peligrosidad; y los dos segundos (de exposición y vulnerabilidad), para localizar y caracterizar los elementos en juego que conducen al mapa final de vulnerabilidad. La superposición de estos dos mapas finales proporciona a la cartografía de riesgos de daños de inundación, tal como se puede apreciar en la figura 2.

Figura 2

ESQUEMA TEÓRICO PARA LA ELABORACIÓN DE MAPAS DE RIESGO DE DAÑOS POR INUNDACIÓN

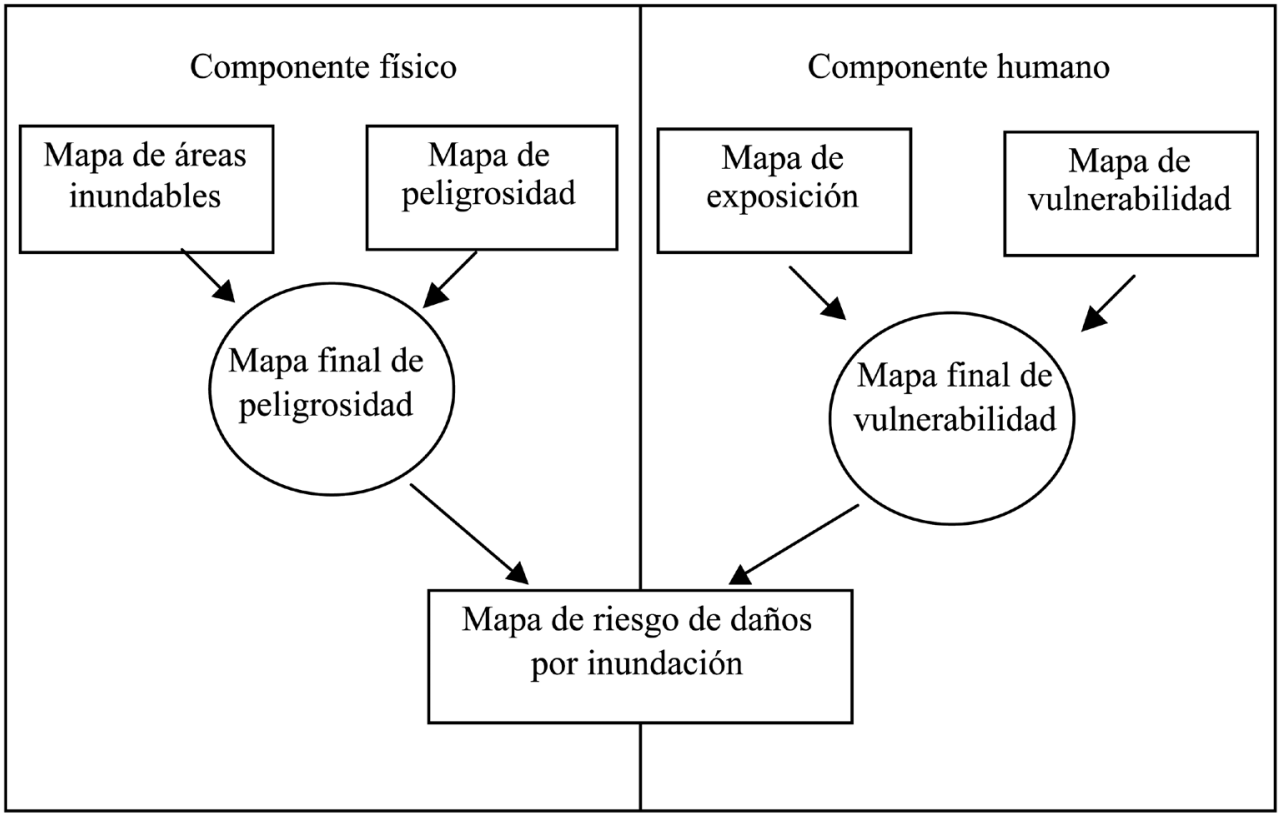

Fuente: Ribera (2004).

Los mapas de riesgo de daños por inundación son una herramienta insustituible para detectar las áreas y los elementos sometidos a riesgo y así poder distribuir los esfuerzos proporcionalmente a los niveles de afectación. Es decir, conocer el nivel potencial de impacto de la inundación sobre los diversos elementos distribuidos en el territorio ayuda a analizar, a tomar decisiones y a desarrollar medidas de gestión y planificación territorial.

\section{MAPAS DE RIESGOS DE INUNDACIÓN EN ESPAÑA}

La producción cartográfica española en materia de riesgos de inundación es cada vez más importante, sin embargo, el avance de su cobertura en el territorio es bastante lento pues la mayoría de los casos se limita a estudios puntuales o zonas piloto. Una de las principales explicaciones a esta situación es la falta de unas directrices específicas para su elaboración, 
lo que dificulta una homogeneidad en los trabajos realizados y, lo que es más grave, plantea serias dificultades en la selección de una escala adecuada a propósito de cada lugar.

Entre los organismo que han desarrollado cartografía sobre riesgos de inundación destaca la del Instituto Geológico y Minero de España (IGME-ITGE). Dicha institución ha venido desarrollando a lo largo de su dilatada historia diversos informes puntuales y estudios generales enfocados a la caracterización y análisis de los riesgos naturales. El máximo apogeo en la producción científico-técnica del IGME-ITGE en el campo del análisis de riesgo de inundaciones se produce en la década de 1980-1990 e inicios del siguiente decenio (Díez y Laín, 1998). Entre los trabajos con expresión cartográfica cada destacar dos tipos de estudios:

- Mapas previsores de riesgos de inundación en núcleos urbanos. Utilizan tres grupos de métodos de forma integrada (histórico-estadístico, hidrológico-hidráulico y geológico-geomorfológico), mediante los cuales obtienen planos de inundabilidad para diferentes periodos de retorno (entre 5 y 500 años) y a grandes escalas (1:2.500, 1:5.000, 1:8.000 o 1:10.000). En la Región de Murcia se encuentran realizados estudios para los municipios de: Puerto Lumbreras, Lorca, Totana y Archena (Pernía, et al, 1987). Los resultados obtenidos en los dos núcleos incluidos en el área de estudio revelan importantes áreas inundables en ambas márgenes de los cursos fluviales del Guadalentín y Nogalte. Por desgracia todos estos trabajos han sido en vano, pues como se verá más adelante, la consideración de los mismos en las políticas de planificación ha sido nula. No existe ningún tipo de vinculación entre estos trabajos y la legislación de ordenación urbana y la ocupación que se viene haciendo de esas áreas inundables es cada vez mayor (vid. Fig. 3 y 4 ).

- Establecimiento de criterios geológicos para la previsión de inundaciones en ámbitos comarcales, provinciales o autonómicos. Se trata de estudios preventivos sobre los factores geológicos (geomorfológicos, sedimentológicos, hidrológico-hidrogeológicos, riesgos asociados...), climáticos y antrópicos que permiten un cierto grado de predicción de la inundación. El resultado son mapas a media-pequeña escala (1:25.000 a 1:500.000) donde se refleja la inundabilidad, puntos conflictivos, elementos expuestos, daños previsibles y riesgos asociados.

Por otro lado, el Centro de Estudios Hidrográficos, integrado en el Centro de Experimentación de Obras Públicas (CEDEX, Ministerio de Fomento), ha estado siempre a la vanguardia metodológica en el análisis hidrológico-hidraúlico de las crecidas fluviales. Sin embargo, su producción cartográfica en el campo de los mapas de riesgos se limita a estudios puntuales o zonas piloto en las que se han ensayado modelos.

Por último, como ya se ha señalado anteriormente, la Dirección General de Obras Hidráulicas, inicialmente desde el Ministerio de Obras Públicas, Transportes y Medio Ambiente (MOPTMA) y, actualmente, desde el Ministerio de Medio Ambiente, ha emprendido el Programa Linde, enfocado a desarrollar el deslinde del Dominio Público Hidráulico (DHP) de los ríos tal y como se contempla en la vigente Ley de Aguas de 1985. La documentación elaborada en el marco del programa Linde, principalmente los mapas del DPH y de las áreas inundables, es básica como cartografía de peligrosidad ante el riesgo de las inundaciones, en su faceta probabilística. Además, al estar esta delimitación estrechamente vinculada a una figura jurídica en vigor, facilita su integración en la planificación territorial, fundamentalmente su necesaria inclusión en el planeamiento municipal. 


\section{LA CARTOGRAFÍA DE RIESGOS DE INUNDACIÓN DE BASE PARA LA PLANIFICACIÓN TERRITORIAL EN LA REGIÓN DE MURCIA}

Los mapas de riesgo de inundación de aplicación en la ordenación del territorio en la Región de Murcia proceden básicamente de dos fuentes:

\subsection{El Atlas Inventario de los Riesgos Naturales en la Región de Murcia}

El Atlas Inventario de los Riesgos Naturales en la Región de Murcia ha sido hasta los últimos años el documento de referencia para cualquier trabajo sobre el territorio desde el año de su realización en 1995. Por desgracia, lo que debería ser un estudio concienzudo sobre estos aspectos, no es más que una aproximación de carácter generalista sobre los principales riesgos que afectan a dicho territorio (movimientos de ladera, seísmos, fenómenos meteorológicos extremos e inundaciones) acompañada de una cartografía a pequeña escala con una aplicabilidad en cuestiones de ordenación casi nula.

El capítulo que el Atlas dedica a los riesgos de inundación, incluye una descripción de la hidrografía y la hidrología de la cuenca del Segura; una explicación sencilla de los mecanismos de las avenidas y un catálogo de las avenidas históricas. El análisis del riesgo propiamente dicho, en teoría, el punto más importante del estudio, se despacha en cuatro breves apartados. El primero de ellos (5.5.1 Zonas de peligrosidad potencial), es una mera clasificación a nivel regional, de los espacios en función del grado (máxima, intermedia y moderada) de su peligrosidad potencial de sufrir inundaciones, en las que sería necesario efectuar una serie de acciones tendientes a evitar o disminuir en lo posible los daños de avenida (5.5.1 Zonas de peligrosidad potencial). Para la localización de dichas zonas emplearon dos fuentes de información:

- Zonas que ya han sufrido en alguna ocasión los efectos de las inundaciones

- Zonas con alguna probabilidad de ser dañadas porque existen causas que pueden producir inundaciones.

Los resultados son los que se presentan en un mapa de zonas inundables (vid. Fig. 5). Como puede advertirse, la escala, 1:500.000 es tan sumamente pequeña que impide su utilización para acciones sectoriales concretas sobre el territorio de referencia. En realidad, se trata de una representación cartográfica sencilla que solo ofrece una idea muy superficial de la impronta del riesgo de inundación en el ámbito de la Región de Murcia. Pese a lo generalista de dicho documento, no se entiende que solo se haya considerado una zona de riesgo fuera de la cuenca vertiente del Segura y sus afluentes (rambla de Benipila en Cartagena) cuando hacía menos de un lustro desde la publicación de este trabajo que las riadas habían azotado con fuerza los municipios de Mazarrón y Águilas, ocasionando incluso la pérdida de vidas humanas. Ni siquiera en el segundo epígrafe del mencionado análisis de riesgo titulado, Cascos urbanos y puntos conflictivos (5.5.2), estas dos últimas poblaciones figuran en el listado de los lugares donde los autores consideran que las avenidas podrían afectar de forma significativa. Entre ellas si que están Puerto Lumbreras y Lorca, con un $10 \%$ y $15 \%$ respectivamente, de casco urbano afectable por las avenidas de 50-100 años de periodo de retorno. Para determinar esa proporción en cada una de las poblaciones estudiadas, utilizaron como base cartográfica los planos de Mapa Topográfico Nacional a escala 1:50.000 y los 


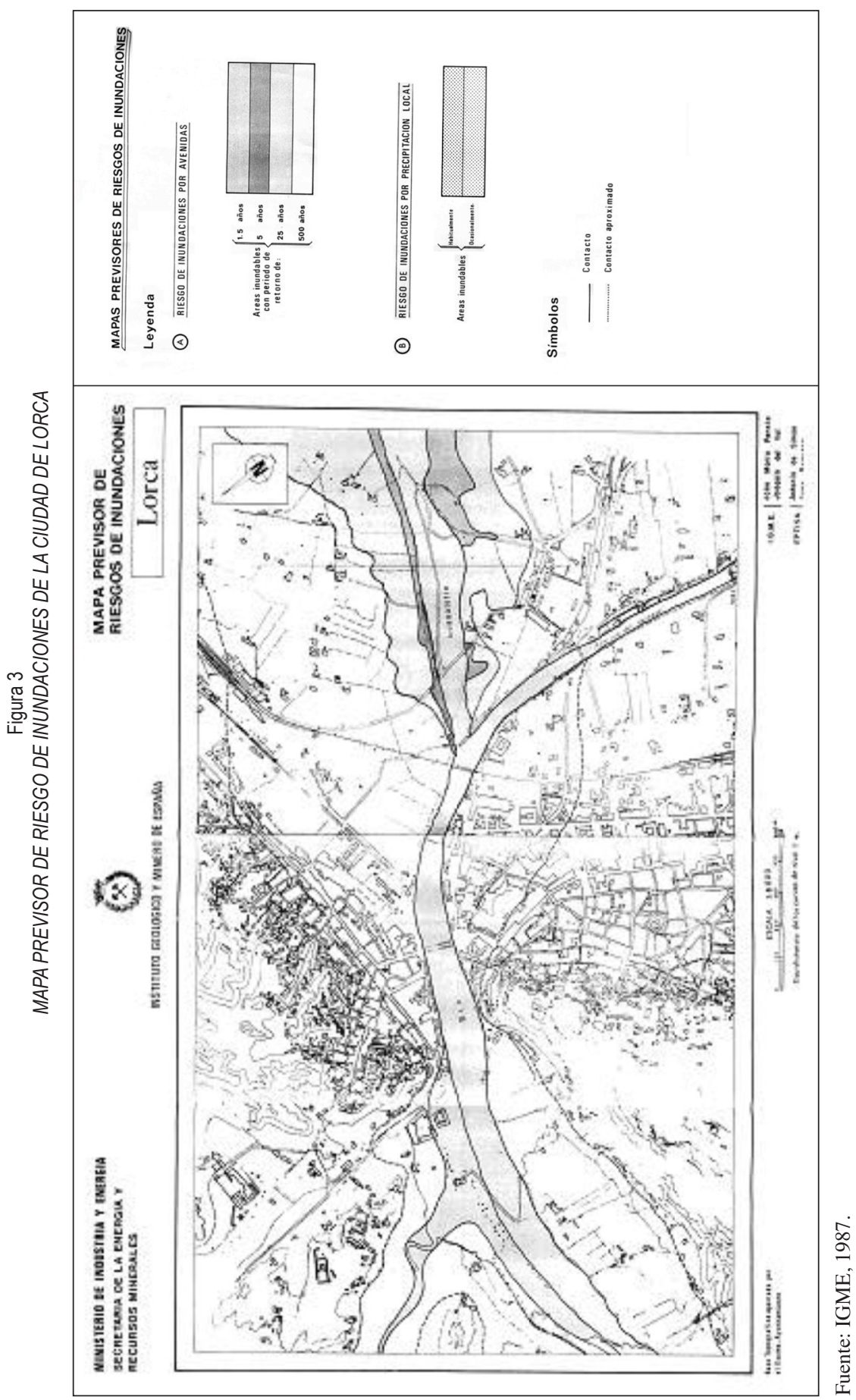




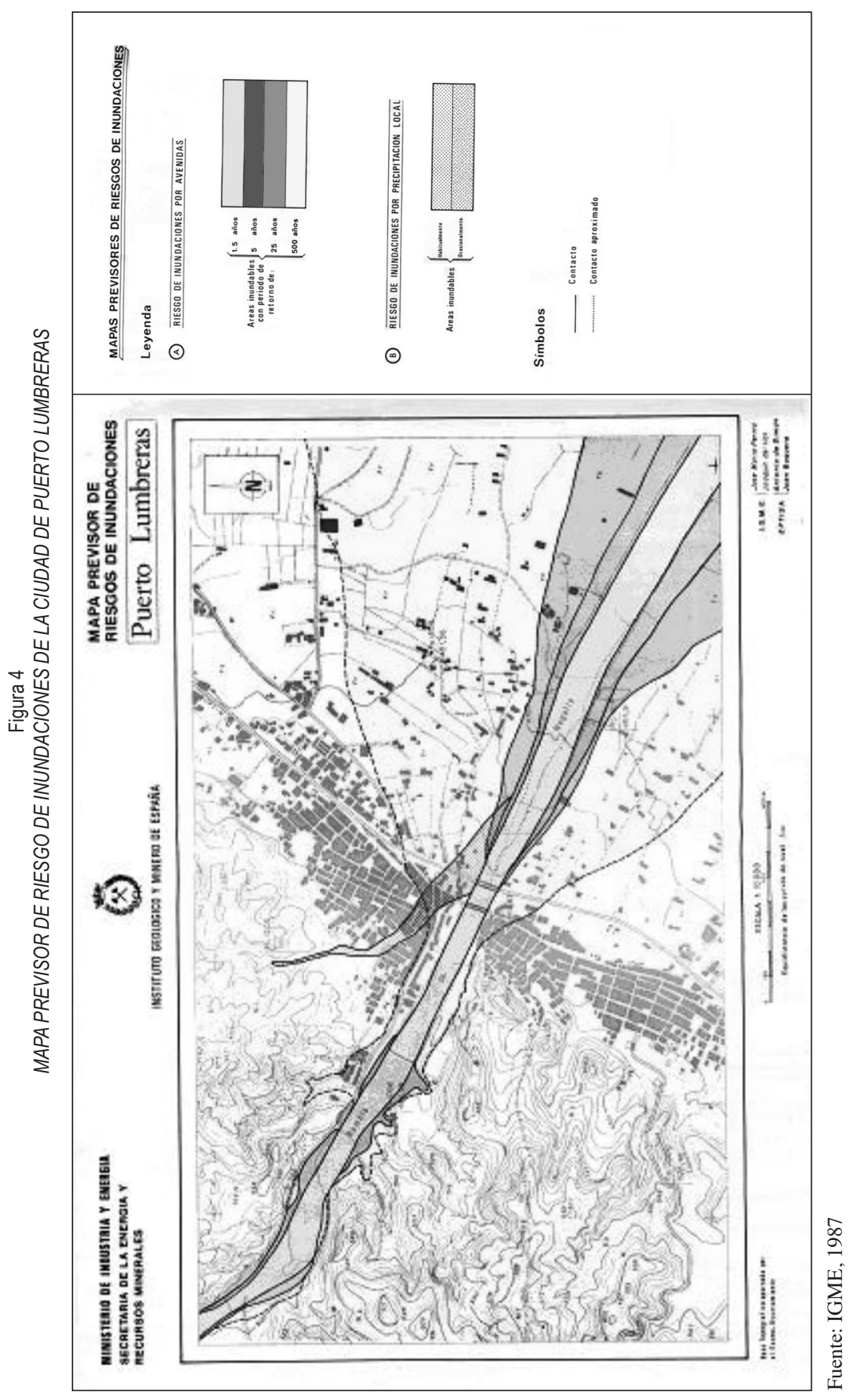


mapas de peligrosidad por inundaciones del trabajo «Geología y prevención de daños por inundaciones» (Ayala et al., 1985). Desafortunadamente, el trabajo no adjunta ninguno de estos mapas de detalle, los cuales, a buen seguro, si que podrían haberse empleado en trabajos de ordenación y delimitación de usos del suelo posteriores.

Por último, se incluyen dos apartado (5.6 Medidas de defensa contra las avenidas y, 5.7Acciones preventivas) íntimamente vinculados entre si, acerca de las medidas de defensa contra avenidas existentes en la cuenca del Segura y las acciones de preventivas que se deberían de llevar a cabo. En este sentido, el estudio se apoya en el trabajo realizado en el año 1.982 por la Dirección General de Obras Hidráulicas para la Comisión Nacional de Protección Civil sobre las acciones necesarias para prevenir y reducir los daños ocasionados por inundaciones en la Cuenca del Segura. En él se recomiendan una serie de acciones encuadradas en dos grandes grupos: métodos estructurales y actividades de gestión.

Las primeras son bien conocidas: embalses de laminación, corrección y regulación de cauces, encauzamientos, canales de derivación, etc Las segundas comprenden actuaciones tales como: conservación de suelos y reforestación, implantación de un sistema de seguros, instalación de sistemas de alarma y previsión, gestión integrada del sistema hidráulico y, un tipo de actuación que califican como zonificación y regulaciones legales, que podría interpretarse como medidas de ordenación territorial. Por desgracia, entre las conclusiones más importantes de dicho estudio, prima el enfoque tecnocrático del problema, y la planificación, a la que no se le dedica ni un párrafo, queda completamente relegada por las actuaciones estructurales.

Conviene señalar que gran parte de las obras y proyectos que se indican como necesarias, ya fueron recogidas anteriormente por el Plan General de Defensa contra Avenidas realizado por la Confederación Hidrográfica en 1.977 y aprobado en 1.986 por la Dirección General de Obras Hidráulicas.

\subsection{El Plan Especial de Protección Civil ante Inundaciones en la Región de Murcia}

El Plan INUNMUR (Plan Especial de Protección Civil ante Inundaciones en la Región de Murcia), sustituye la cartografía obsoleta del IGME y se erige como el documento que se ha de consultar en cualquier proceso de delimitación del suelo en virtud del artículo 12 de la ley estatal del suelo de 2007 siempre y cuando el organismo de cuenca competente no dicte lo contrario o disponga de una delimitación sustitutoria.

Los mapas que se incluyen en el documento de Protección Civil Regional, quedarían clasificados en el grupo de «mapas de riesgos de daños por inundación». Para facilitar su realización se dividen en dos grupos, los de cuencas reguladas y no reguladas. El análisis de riesgo, para los dos tipos de cuencas, se estructura en tres apartados principales:

\section{a) Estudio hidrológico:}

El objetivo de ese estudio es obtener los caudales de avenida para los periodos de retorno de 50, 100 y 500 años en puntos característicos de las cuencas. Como hipótesis de partida para el estudio hidrológico de las cuencas reguladas y siguiendo criterios propios de Protección Civil, se ha considerado los resguardos en los embalses de uso múltiple, y vacíos en los 


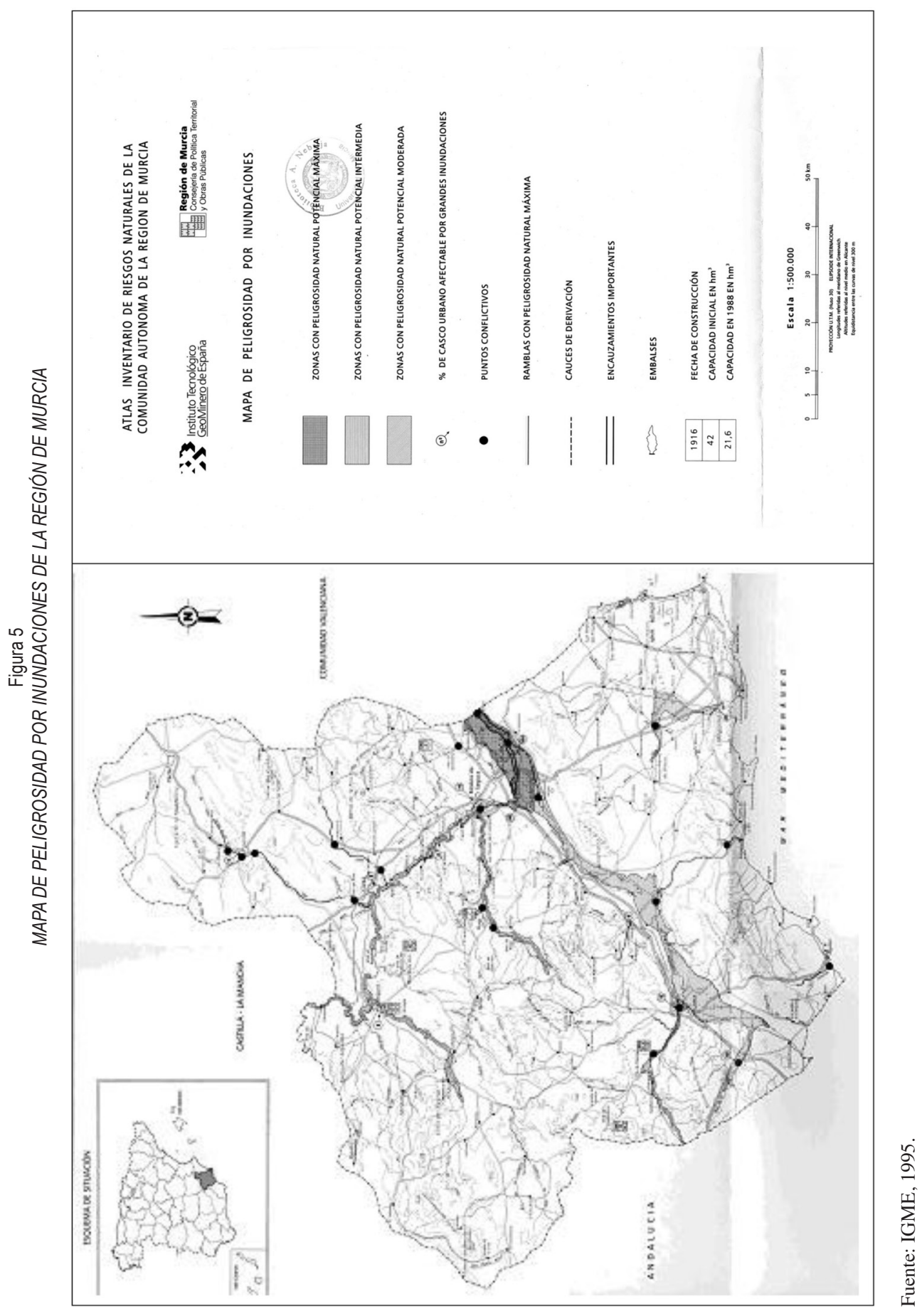


específicamente construidos para defensa de avenidas, contemplando a su vez la simultaneidad en el funcionamiento de los mismos, si bien se han tenido en cuenta los coeficientes de simultaneidad adecuados a esta situación. Tanto en los cauces regulados como en los no regulados la estimación de caudales se ha basado exclusivamente en datos meteorológicos y en las características fisiográficas de la cuenca, utilizando para ello un método hidrometeorológico en el que se han considerado los siguientes pasos:

- Caracterización geomorfológica de las cuencas, incluyendo la obtención de los valores representativos de su comportamiento hidrológico, que se han reflejado en el parámetro «número de curva» de acuerdo con la metodología del Soil Conservation Service de los Estados Unidos.

- Estimación de los parámetros asociados con la propagación de las avenidas en los tramos de cauce.

- Deducción, mediante análisis estadístico y partiendo de la documentación existente, de los valores de la lluvia máxima en 24 horas para diferentes períodos de recurrencia y de los hietogramas de cálculo asociados a las tormentas características.

- Construcción y calibración de un modelo de simulación hidrológica basado en el programa HEC_1, de acuerdo con la modelización desarrollada por el Hydrologic Engineering Center (HEC), para simular el proceso de transformación de la precipitación en escorrentía y su propagación a lo largo de los cauces regulados y el módulo r.watershed de GRASS (Geographic Ressources Analysis Support System) para las cuencas en régimen hidráulico natural

- Inclusión en el modelo HEC-1 la simulación de la laminación en los embalses existentes.

- Deducción, a partir del modelo, de los valores de caudal máximo correspondientes a distintos períodos de recurrencia en los tramos objeto de estudio.

\section{b) Estudio hidráulico:}

El objetivo de este estudio es delimitar las zonas que quedarían inundadas por las avenidas de periodo de 50, 100 y 500 años previamente calculadas, obteniendo así las zonas de inundación frecuente, ocasional y excepcional conforme a la denominación establecida por la Directriz Básica en el apartado 2.2.1.

- Partiendo de la cartografía, del Servicio de Cartografía de la Consejería de Obras Públicas, Vivienda y Transporte, a escala 1:5000 y para algunos tramos en particular la cartografía, proporcionada por el Servicio de Cartografía del Ayuntamiento de Murcia, a escala 1:1000 y 1:500 se ha construido un modelo de simulación hidráulica de los cauces y las correspondientes llanuras de inundación.

a) Modelo de simulación MIKE 11 desarrollado por DHI Water\&Inveronment (Dinamarca) para el caso del río Guadalentín entre la presa de Puentes y el embalse de José Bautista que ha sido modelizado en régimen variable y con un modelo cuasibidimensional, debido a la especial morfología del cauce y de la cuenca.

b) Modelo de simulación bidimensional completo SFCUZ 2D, para el tramo que discurre desde la confluencia del río Guadalentín con el río Segura hasta el límite con Alicante. 
c) Modelo de simulación HEC-RAS, unidimensional y en régimen permanente para el resto de las cuencas tanto reguladas como no reguladas de la Región de Murcia.

Se han tenido en cuenta en el modelo las características hidráulicas de los puentes que pudieran determinar influencia sobre el régimen hidráulico aguas arriba. Una vez obtenidos los valores de la cota de agua correspondientes a los distintos caudales máximos según el período de recurrencia de la avenida, se ha representado cartográficamente, deduciendo, en consecuencia, la extensión de las zonas inundables en cada tramo. Los resultados se han reflejado, como establece la Directriz Básica, sobre la cartografía oficial a escala 1:25000 (Anexo II).

\section{c) Análisis del riesgo:}

Se clasifican las zonas de riesgo según los criterios de la Directriz Básica, estos son:

- La peligrosidad de la inundación, considerando de un lado la frecuencia a partir de la estimación de caudales para los diferentes periodos de recurrencia $(50,100$, y 500 años) y de otro la severidad tomando como parámetro el nivel alcanzado por las aguas en cada caso.

- La exposición al riesgo, identificando y clasificando los elementos que existen en las zonas que quedarían inundadas por las diferentes avenidas (50, 100 y 500 años). Se han identificado y clasificado en concreto núcleos de población, instalaciones industriales y comerciales, viviendas aisladas, infraestructuras y servicios esenciales.

Siguiendo los criterios de la Directriz Básica a los efectos del presente Plan, se han considerado:

Zonas A-1. Núcleos urbanos en los que la avenida de cincuenta años de periodo de retorno alcance o supere $\operatorname{los} 30 \mathrm{~cm}$.

Zonas A-2. Núcleos urbanos en los que la avenida de cien años de periodo de retorno alcance o supere $\operatorname{los} 30 \mathrm{~cm}$.

Zonas A-3. Núcleos urbanos en los que la avenida de quinientos años de periodo de retorno alcance o supere $10 \mathrm{~cm}$.

Zonas A. Viviendas aisladas, instalaciones comerciales o industriales y/o servicios básicos en los que la avenida de cincuenta años de periodo de retorno alcance o supere los $30 \mathrm{~cm}$.

Zonas B. Viviendas aisladas, instalaciones comerciales o industriales y/o servicios básicos en los que la avenida de cien años de periodo de retorno alcance o supere $\operatorname{los} 30 \mathrm{~cm}$.

Zonas C. Viviendas aisladas, instalaciones comerciales o industriales y/o servicios básicos en los que la avenida de quinientos años de periodo de retorno alcance o supere los 30 $\mathrm{cm}$.

Para cada una de las áreas de riesgo se han elaborado unas fichas (Anexo III), en las que se presentan los siguientes datos:

- Datos administrativos y geográficos: Término municipal, coordenadas UTM del inicio y final del tramo afectado.

- Datos hidráulicos:

- Cauces regulados: cotas alcanzadas por las láminas de agua en el comienzo y en final del tramo afectado para los periodos de retorno de 50, 100 y 500 años, calados representativos en el elemento afectado o calados representativos en el tramo 
inicial y/o final del polígono afectado, en el caso de que se hayan agrupado varios elementos.

- Cauces no regulados: calados en el centro del polígono que representa el elemento afectado para los tres periodos de retorno de 50, 100 y 500 años.

- Nivel de Riesgo según la clasificación referida en la Directriz Básica de Protección Civil.

- Datos de población asignado a cada elemento afectado de acuerdo con los datos del INE 2004.

En algunos casos, se han representado como áreas de riesgo, zonas en las que el calado significativo es inferior a $30 \mathrm{~cm}$, debido a que se han considerado otros aspectos como calados máximos, la geometría de la inundación respecto al elemento (no es lo mismo una inundación lateral que una vivienda totalmente rodeada), elementos situados en puntos bajos, zonas urbanas de uso residencial con garajes, etc.

De forma añadida se señalan otros elementos de interés (puntos conflictivos), considerando como tal aquellos, en los que a consecuencia de modificaciones hechas por el hombre, o por la propia morfología del terreno pueden producir situaciones que agraven de forma substancial los efectos de la inundación.

El estudio de cada una de las variables que se representan cartográficamente se hace en base a los resultados del cálculo matemático estadístico de los periodos de retorno. Este método puede que sea un formalismo ideal para determinar el Dominio Público Hidráulico (como así sucede en el caso de España a la hora de señalar si una inundación es o no es mayor de la de 500 años de periodo de retorno) y así evitar situaciones legales de indefinición, sin embargo, cuando están en juego las vidas y los bienes de las personas, la importancia de dicho procedimiento debería ser menor en cuanto a su aplicación, puesto que desde el punto de vista científico adolece de cierto rigor y en muchos casos la plasmación cartográfica no se aproxima a la realidad por las deficiencias que a continuación se señalan. Según la opinión de Olcina (2007), la función matemática-estadística de los periodos de retorno tiene varios problemas, uno de ellos es el de los ajustes de las distribuciones de datos pluviométricos. En concreto, cuando uno de estos valores se desvía claramente de la ley que parecen seguir los restantes, el ajuste obliga en muchos casos a aumentar el periodo de retorno, pues se le ha de asignar el máximo periodo a dicho valor. Por ende, pueden existir abultadas series de datos que por si solas pueden producir inundaciones, pero al darse una cifra extrema, ese primer grupo puede quedar enmascarado. Con lo cual el traslado de dicha información sobre el mapa, no suele reflejar con fidelidad la realidad.

El mismo autor indica también al respecto, que dichos estudios probabilísticos raramente pueden ser contrastados pues la series en las que se apoyan apenas superan los cien años, por lo que esta práctica puede resultar científicamente criticable al basarse en la mera suposición de que la Naturaleza deba necesariamente ajustarse a una formulación matemática teórica, especialmente cuando el periodo de retorno asignado con este sistema supera el doble de la longitud temporal de la serie analizada.

La valoración del riesgo de inundación que se hace en la cartografía presentada por el Plan INUNMUR demuestra las carencias hasta el momento señaladas. A continuación se analiza detalladamente cuales son los puntos débiles y flaquezas de cada uno de los mapas elaborados para algunos de los núcleos urbanos de la Región de Murcia más afectados por las riadas. 


\subsubsection{Puerto Lumbreras}

El caso de Puerto Lumbreras llama la atención, la reducida superficie que el estudio estima como inundable, ya que la última riada extraordinaria, en concreto, la de 19 de octubre de 1973, superó con creces dichos límites. El mapa del IGME (Pernías, et al.; 1987) comentado anteriormente, si refleja en cierto modo la envergadura de este suceso. Resulta un tanto extraño, que dos documentos realizados siguiendo un procedimiento de elaboración similar, distan en gran medida en sus resultados finales. Una explicación coherente a esta situación es que las actuaciones preventivas realizadas tras la citada riada para solventar los problemas evidenciados por los excesos de agua, pueden tener un efecto paliativo sobre los procesos de desbordamiento, hecho que han considerado los cartógrafos del Plan INUNMUR.

Sin embargo, el principal problema que se advierte en el mapa objeto de análisis es que, se ha obviado por completo una cuestión de carácter social que tiene influencia directa sobre el comportamiento de la escorrentía y, por ende, sobre la superficie inundable estimada en los análisis estadísticos del mapa de Protección Civil. El intenso proceso de desorganización y abandono de las formas tradicionales de captación de aguas en la cabecera de la rambla de Nogalte y su abanico aluvial, favorecen el aumento acelerado de los procesos de escorrentía, lo que contribuye, a buen seguro, a incrementar la superficie inundable final que se refleja en el documento y, por ende, la peligrosidad del fenómeno.

La hipótesis anteriormente expuesta ha sido recientemente respaldada por Ortega et al. (2009), en cuyo estudio, «Funcionamiento de la rambla de Nogalte (Murcia) durante avenidas. Implicaciones para la cartografía de peligrosidad por riesgo de avenidas» los caudales obtenidos en la rambla de Nogalte a partir de la modelización hidrológica no se corresponden bien con los datos de la avenida de 1973 y de sus efectos ni con las condiciones de la cuenca de recepción, tanto por su morfología elongada y tiempo de concentración alto (pendiente moderada y longitud alta del cauce). Según dichos autores, habría que dar más importancia de la carga sólida arrastrada durante el episodio, no tenida en cuenta en la modelización hidráulica. Las condiciones de erosión en los suelos de la cuenca de Nogalte fueron extremas, favorecidas por las roturaciones con falta de protección del suelo. La facilidad de lavado de los productos finos, unidos a la capacidad de floculación de arcillas, permitió la alta y súbita concentración de finos en suspensión, y así mismo la rápida extinción de la avenida y el depósito de toda la carga de limos al llegar al abanico que representa una zona de acreción sin cauces jerarquizados.

\subsubsection{Lorca}

La representación cartográfica de la ciudad de Lorca muestra algunas inexactitudes que merecen ser comentadas con atención. En primer lugar, no se entiende que el tramo del cauce a su paso por la ciudad sea considerado con la categoría A3 (aquellas zonas en las que la avenida de quinientos años produciría graves daños a núcleos urbanos) pese a que, desde la propia administración, se afirma que las obras llevadas a cabo dentro del último Plan de Defensa de Avenidas de la cuenca del Segura son suficientes para evitar futuros desbordamientos del río Guadalentín a su paso por Lorca. 


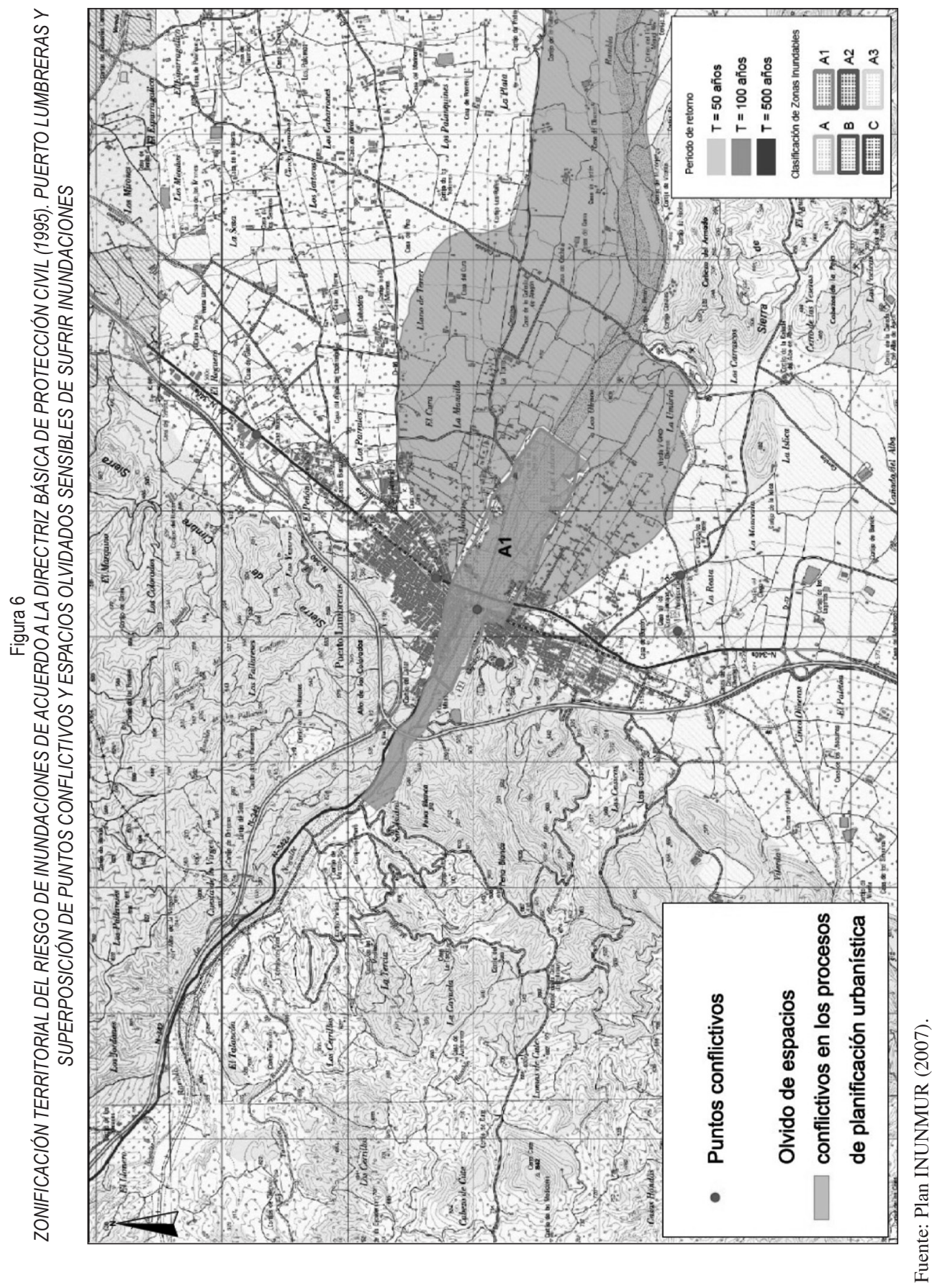




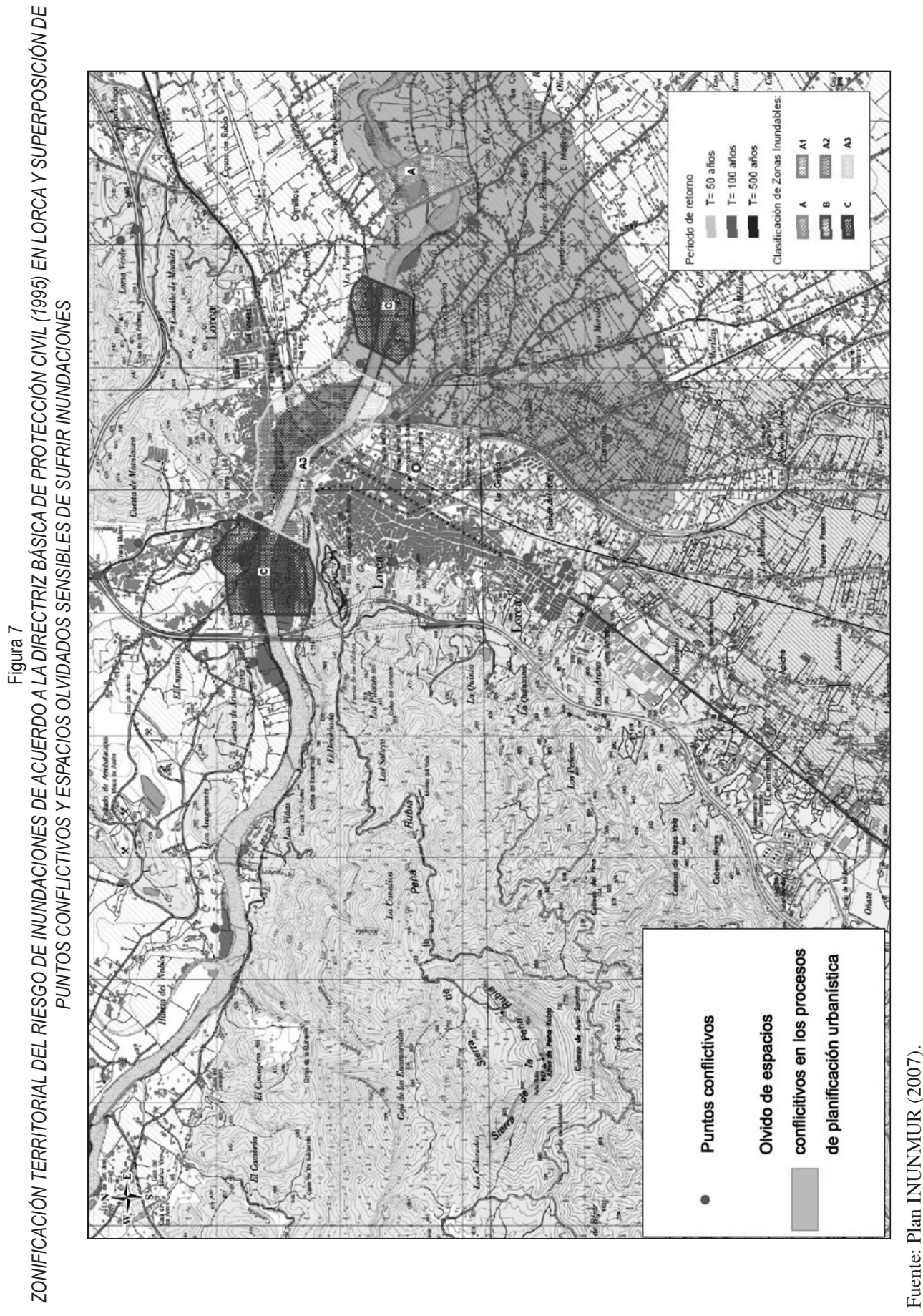


Por otro lado, sorprende que dicha superficie no se encuentre unificada a los siguientes sectores calificados como: zona $\mathrm{C}$ en las proximidades de la diputación de Pulgara, y zona A en Puente del Peregilero. La explicación la encontramos en que el análisis del riesgo se hace en base a una avenida tipo considerando un buen funcionamiento de los embalses de cabecera, Valdeinfierno y Puentes, por lo que el espacio inundable que comprenden esos claros, indican que no existe nada que las aguas puedan afectar allí. Sin embargo, conviene indicar, que de producirse un evento pluvial intenso y localizado aguas abajo de dichas presas (cuenca vertiente aproximada de $404,4 \mathrm{Km}^{2}$ ), la superficie inundable y por tanto afectada por las avenidas, sería considerablemente mayor, pues en la actualidad, como puede advertirse en la figura 7, se trata de uno de los principales polos de crecimiento y permanece completamente desprotegida frente a este tipo de eventos.

Por otra parte, las diputaciones lorquinas situadas al borde del llano de inundación, como es el caso de La Hoya, en el sector septentrional, y Purias, en el meridional, han experimentado un crecimiento de sus viviendas acentuado en estos últimos años, que ha provocado la integración en su trama urbana de alguno de los barrancos que drenan las vertientes de los flancos orográficos del valle. En las cuencas de este tipo de cauces se han desarrollado varias campañas de repoblación hidrológico forestal entre 1972 y 1995 que, pese a los intentos por reducir el coeficiente de escorrentía de dichas laderas, su efectividad final ha sido más bien reducida debido a una mala planificación en su proyección. Según Conesa y Lorenzo (2007), los diques de contención, pueden ocasionar algunos efectos negativos como la erosión y profundización del lecho aguas abajo de los diques que afectan al ecosistema fluvial y, por ende, sobre las poblaciones que se acomodan en sus riberas. Este hecho ha sido completamente olvidado en el Plan de Protección Civil a pesar de que, al menos en tres ocasiones (7 septiembre de 1989, 15 octubre de 1989 y 26 de septiembre de 1997), los mencionados núcleos urbanos se vieron afectados en mayor o menor medida por las avenidas. Es posible presuponer que deben de ser los planes de emergencia municipales los responsables de hacer las pertinentes indicaciones en este sentido para que estas poblaciones no permanezcan desprotegidas.

\subsubsection{Mazarrón}

El mapa de la ciudad de Mazarrón y Puerto de Mazarrón presenta una delimitación de las zonas inundables que se asemeja bastante a los espacios tradicionalmente afectados por los desbordamientos de la rambla de las Moreras. En concreto, su desembocadura, tristemente célebre por el desastre del camping de Bolnuevo, aparece cubierta por una gran sombra que indica el riesgo que comporta su ocupación. Además, también se incluyen como lugares sensibles de sufrir los efectos de las avenidas, los dos puentes que ponen en contacto ambas márgenes del último tramo de la rambla. Desafortunadamente, el mapa queda incompleto pues no considera los problemas que comporta el drenaje de las lluvias in situ sobre los terrenos donde se localiza la urbanización Bahía, cuyos problemas ya se han comentado. No se comprende que, otras ciudades de la Región afectadas por fenómenos similares como San Pedro del Pinatar o Los Alcázares si hayan sido objeto de análisis, y este caso haya pasado completamente desapercibido. 


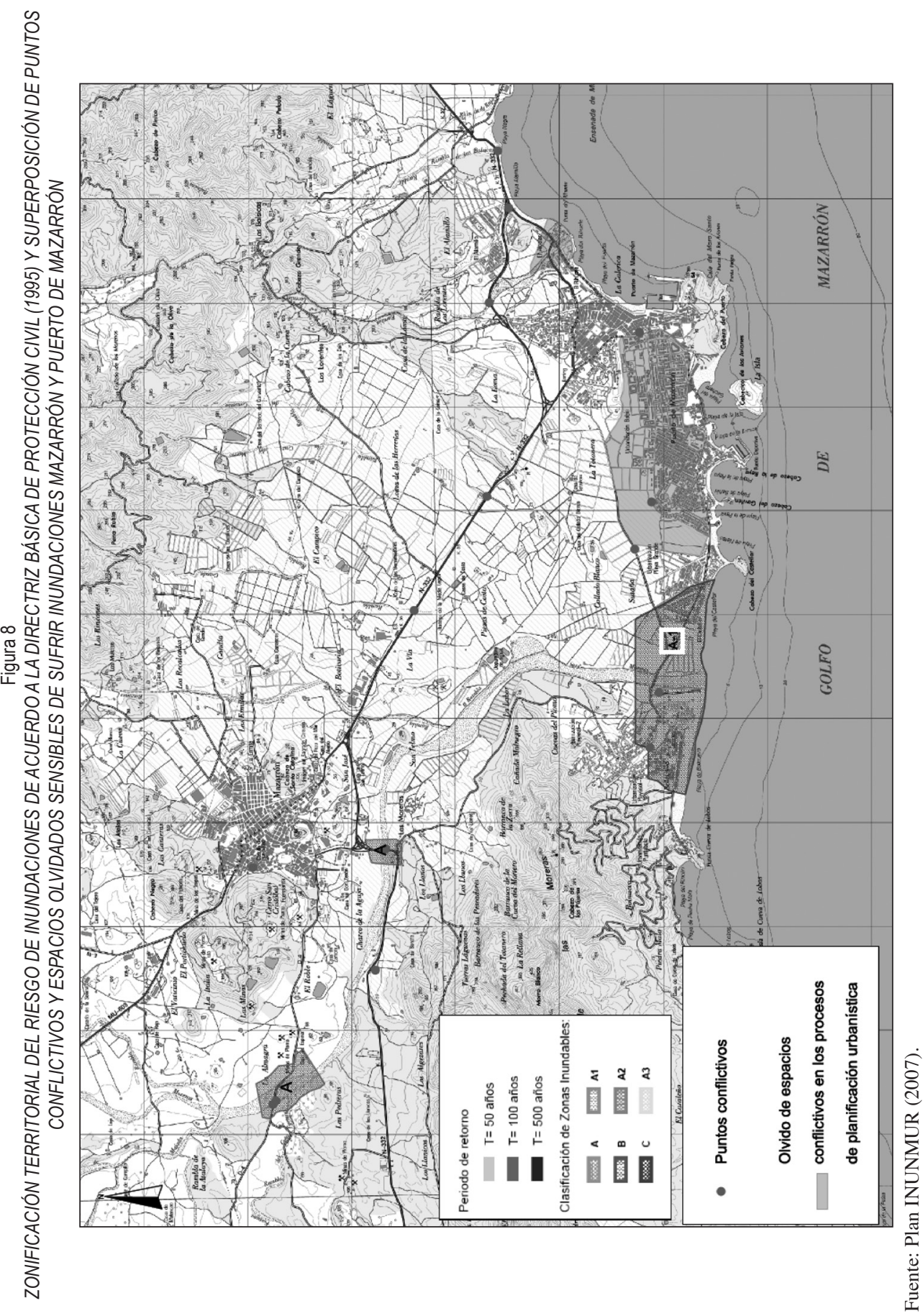




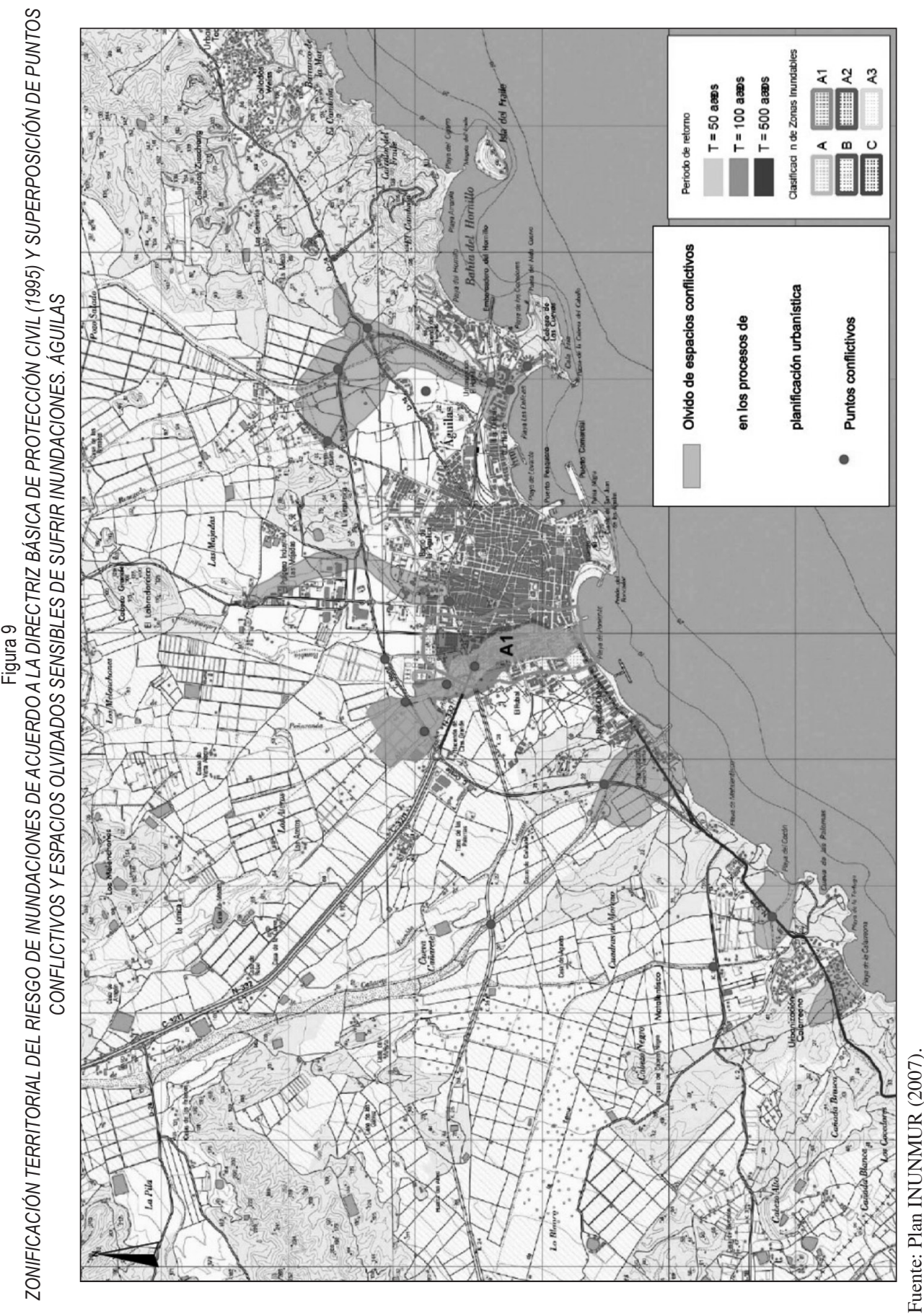




\subsection{4. Águilas}

La ciudad de Águilas presenta, también, una consideración del riesgo insuficiente en su representación cartográfica. La delimitación de zonas inundables se concentra entorno a los efectos que podría ocasionar la onda de crecida extraordinaria de la cuenca de PeñarandaLabradorcico, aunque ya se ha comprobado, desgraciadamente, en más de una ocasión, que las avenidas generadas por las ramblas vecinas de las Majadas y el tramo final unificado de los aparatos fluviales de Renegado y Culebras, generan serios problemas en la población y las viviendas aguileñas. Se sobrentiende que los autores del mapa confían en el buen funcionamiento de las obras de modificación del trazado y entubación con las que cuentan esos últimos cursos comentados, sin embargo, en mayo de 2006, éstas demostraron sus limitaciones y los terrenos que en teoría protegen fueron seriamente afectados.

Esta situación demuestra, una vez más, el escaso valor que ha tenido el trabajo de campo en el proceso de realización de este tipo de documentos. Un simple recorrido por el sector septentrional de la cuenca neógena de Águilas hubiese servido para despertar la percepción del riesgo más allá de lo que los sistemas de información geográfica desprenden como resultados. El campo aguileño ha sufrido uno de los procesos de artificialización del territorio más intensos de la Región en estas últimas décadas, lo que motiva que las medidas de carácter estructural, adoptadas tras la catástrofe de octubre de 1989, hayan quedado obsoletas.

A la vista de lo anteriormente expuesto se deduce que, la realización de una delimitación de zonas inundables y espacios en riesgos no debe basarse únicamente en el procedimiento estadístico de los periodos de retorno. Apostar en exclusiva por este método, pese a las carencias demostradas, reduce en gran medida las posibilidades del plan de Protección Civil regional para ofrecer una zonificación del riesgo rigurosa que pueda ser aplicada en los procesos de ordenación del territorio municipal. Se precisan enfoques integrados, capaces de manejar, interpretar y valorar diferentes variables: físicas (hidrológicas, climáticas, biogeográficas), territoriales (usos del suelo e infraestructuras), humanas (percepción del riesgo). Los trabajos de campo son indispensables, máxime si se quiere ofrecer una valoración real de los niveles de riesgo con plasmación cartográfica.

\section{EL SISTEMA NACIONAL DE CARTOGRAFÍA DE ZONAS INUNDABLES}

El 26 de noviembre de 2007 entró en vigor una nueva Directiva europea sobre la evaluación y gestión de las inundaciones (Directiva 2007/60/CE del Parlamento Europeo y del Consejo, de 23 de octubre de 2007, relativa a la evaluación y gestión de los riesgos de inundación) cuya transposición al derecho español debe realizarse antes del 26 de noviembre de 2009. Con la puesta en marcha del Sistema Nacional de Cartografía de Zonas Inundables por parte del MARM (Ministerio de Medio Ambiente y Medio Rural y Marino), España se convierte en uno de los primeros países europeos en aplicar los principios de dicha Directiva.

Con la elaboración del Sistema Nacional de Cartografía de Zonas Inundables se pondrán a disposición del ciudadano, a través de Internet, todos los mapas de peligrosidad de inundaciones realizados por el Ministerio de Medio Ambiente, y Medio Rural y Marino y aquellos que aporten las Comunidades Autónomas dentro de sus competencias. Este Sistema generará 
y facilitará la consulta de toda la cartografía de zonas inundables disponible en el territorio nacional. Será una herramienta básica en:

- La protección del Dominio Público Hidráulico por los Organismos de Cuenca y la defensa de las zonas con peligrosidad de inundaciones, sirviéndoles de una herramienta básica para la emisión de informes sobre autorizaciones en el Dominio Público Hidráulico y sus zonas asociadas y la gestión de avenidas en conexión con los Sistemas Automáticos de Información Hidrológica.

- La planificación adecuada de las actuaciones de defensa frente a inundaciones, identificando puntos vulnerables sobre los que se deba actuar prioritariamente.

- La planificación y gestión de las áreas inundables en el ámbito de sus competencias, a las autoridades de Protección Civil.

- Proporcionar esta información a otras administraciones (especialmente las autoridades urbanísticas y de planificación territorial) y promotores sobre las zonas inundables existentes y el riesgo que existe al construir en ellas.

- Dar a conocer a los ciudadanos la peligrosidad de cada zona existente, de forma que se le dote de información suficiente para mejorar la transparencia de la gestión de todas las administraciones.

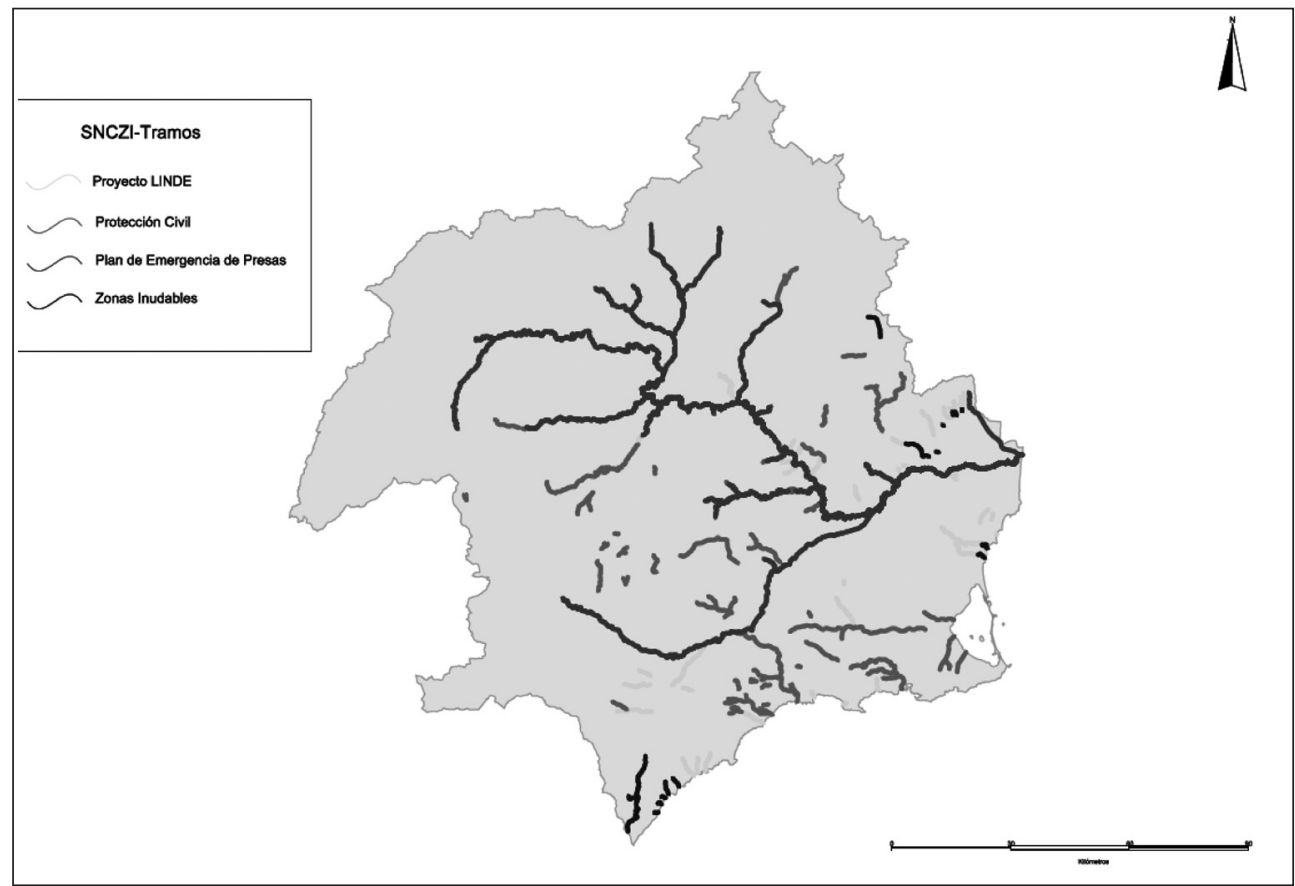

Fuente: MARM. 
En cuanto al desarrollo del Sistema Nacional de Cartografía de Zonas Inundables se está realizando en dos fases: La primera consiste en la identificación y recopilación de todos los estudios de zonas inundables ya realizados, bien sean elaborados por el MARM o por las Comunidades Autónomas.

La segunda fase consistirá en realizar la generación de nueva cartografía de zonas inundables a partir de los tramos en riesgo. Esta fase comenzará a ejecutarse en las cuencas hidrográficas del Cantábrico y del Júcar y, progresivamente, en el resto de cuencas hidrográficas que gestiona en MARM a través de las Confederaciones Hidrográficas. Para la cuenca del Segura, el ministerio de Medio Ambiente, y Medio Rural y Marino ha licitado por más de tres millones de euros dichos trabajos y se estima que se tendrán que delimitar 1.250 kilómetros de cauces, lo que se traducirá en un total de 100.000 hectáreas cartografiadas.

Para ejecutar este último paso se delimitarán los siguientes espacios:

1. Determinación del DPH mediante criterios hidrológicos, geomorfológicos y ambientales.

2. Vía de flujo preferente, que podrá, en caso necesario a establecerse como zona de policía

3. Avenidas asociadas a distintos períodos de retorno, en régimen natural y alterado.

Parece entonces que el método elegido completa definitivamente las carencias que hasta ahora han sido mencionadas. Si se siguen los pasos establecidos en este nuevo proyecto, se dispondrá de una cartografía eficiente y lo suficientemente fiable para poder precisar por primera vez las zonas sensibles de sufrir inundaciones en consonancia con lo que sucede en la naturaleza. Por tanto, tan solo queda confiar en que los futuros planes de ordenación municipal apliquen con buen criterio las indicaciones cartográficas que se hagan para cada caso con el principal objetivo de integrar con todas las garantías de seguridad al riesgo de inundación en el proceso de ordenación territorial.

\section{VALORACIONES FINALES}

Los mapas de riesgo de inundación son una herramienta insustituible para detectar las áreas y los elementos sometidos al mismo y así poder distribuir los esfuerzos proporcionalmente a los niveles de afectación. Es decir, conocer el nivel potencial de impacto de la inundación sobre los diversos elementos distribuidos en el territorio ayuda a analizar, a tomar decisiones y a desarrollar medidas de gestión y planificación territorial.

La producción cartográfica española en esta materia ha experimentado un gran avance en las dos últimas décadas gracias al avance en las técnicas empleadas para modelizar cuencas hidrográficas naturales. En este sentido, el número de softwares dedicados a dicho cometido ha ido creciendo en número, y en la actualidad se dispone de un variado grupo de instrumentos de carácter lucrativo privado como: MIKE-SHE, MIKE 11 o SOBEK o de forma gratuita como: AVSWAT-2000, ArcHydro, TauDEM, MODFLOW-2000, HidroSIG y, sobre todo, la familia de programas desarrollado por el Centro de Ingeniería Hidrológica (Hydrologic Engineering Center) del cuerpo de ingenieros de la armada de los EE.UU. (US Army Corps of Engineers).

Desafortunadamente, la cobertura cartográfica del territorio español es bastante reducida, pues la mayoría de los casos se limita a estudios puntuales o zonas piloto. La principal 
explicación a esta situación es la de unas directrices específicas para su elaboración, lo que dificulta una homogeneidad en los trabajos realizados y, lo que es más grave, plantea serias dificultades en la selección de una escala adecuada a propósito de cada lugar.

En cuanto a la metodología para la delimitación de los espacios inundables existen también ciertos defectos de base que dificultan la realización de mapas precisos y útiles para ser empleados en los procesos de planificación urbana. Hasta el momento el deslinde de zonas afectadas por el riesgo de inundación se ha hecho en base al cálculo de los periodos de retorno o recurrencia de caudales máximos. Se trata de un procedimiento estadístico avanzado en el que se apoyan todos los programas informáticos anteriormente señalados pero que, si no es completado con los trabajos de campo pertinentes, sus resultados finales adolecen de cierto rigor y en muchos casos la plasmación cartográfica final no se aproxima a la realidad.

Otro de los problemas que restan fiabilidad a los mapas de riesgos de inundación, es la reducida precisión de los modelos digitales del terreno sobre los que se plasman los resultados de los periodos de retorno. En la actualidad, los resultados de dichos cálculos, se representan sobre topografías simuladas informáticamente en base a curvas de nivel de 10 o 5 metros. Se trata de valores demasiado grandes para ajustarse a la realidad de cauces naturales como la red de ramblas del Sur de la Región de Murcia, las cuales, han sido intensamente transformadas y cuya delimitación hidrográfica de los principales colectores exigen una escala mínima de 1:5.000 con empleo de curvas de nivel de 1 metro para poder reconstruir de forma más o menos aparente sus recorridos.

Por otro lado, dentro del ámbito semiárido los modelos hidrográficos no suelen contemplar la elevada carga sólida que arrastran las aguas en avenida y la diferencia de comportamiento entre zonas encauzadas y de abanico, lo que hace muy complejo introducir estos aspectos en los mapas de peligrosidad.

De acuerdo a todo lo anterior, para poder realizar un tipo de delimitación de territorios de riesgo a escala local eficaz y útil para su empleo en la ordenación territorial es necesario mejorar: el conocimiento de los elementos geográficos intervinientes; el reconocimiento del peligro natural que afecta a un territorio y el grado de riesgo a partir del repaso minucioso de eventos históricos. Con dicho análisis es posible por tanto elaborar una cartografía primera de espacios geográficos con riesgo en virtud del grado de ocupación antrópica del suelo.

Dichas tareas han de ser completadas con el trabajo exhaustivo de campo y percepción del riesgo. En esta fase ha de compararse y matizarse sobre el terreno la valoración de espacios de riesgo realizada en la etapa anterior. El trabajo de campo y la encuesta personal con grupos sociales potencialmente vulnerables ante un peligro natural es una herramienta esencial de cualificación del análisis de riesgo. A partir del trabajo de campo se puede matizar el grado de riesgo otorgado a un espacio geográfico. El conocimiento de la percepción social del riesgo puede orientar sobre las estrategias de reducción o de gestión de las emergencias.

Asimismo, es también importante conocer las medidas de defensa puestas en marcha, oficiales y privadas, para reducir el riesgo, valorar su efectividad con vistas a proponer mejoras en las mismas o completarlas con nuevas propuestas. Ello incluye también la revisión de la legislación existente para la prevención de los desastres naturales.

Una vez considerados todos y cada uno de los aspectos mencionados, es el momento de relacionarlos sobre el papel con los resultados estadísticos obtenidos por los periodos 
de retorno. Finalmente la cartografía debe de recoger al menos, los siguientes mapas: cartografía de causas; cartografía de espacios de riesgo con su grado de riesgo y cartografía de prácticas de defensa.

Según los criterios de desarrollo del Sistema Nacional de Cartografías de Zonas Inundables, parece que se está desarrollando finalmente un instrumento que corrige las deficiencias hasta el momento comentadas. No obstante, dicho proyecto no puede dilatarse mucho en su ejecución pues los procesos de ocupación del suelo continúan imparables y los espacios sensibles de sufrir inundaciones siguen aumentando de forma progresiva como ha quedado demostrado por ejemplo tras las últimas inundaciones sufridas en el mes agosto de 2010 en el levante español.

\section{BIBLIOGRAFÍA}

AYALA CARCEDO, F.J.; DURÁN; J.J.; ELIZAGA, E.; GARZÁN, G. et al. (1985): Geología y prevención de daños por inundaciones. Madrid, IGME.

CAMARASA BELMONTE, A.M.; SALAS REY, F.J. y CHUVIECO SALINERO, E. (2001): «Información geográfica y riesgos naturales». El Campo de las ciencias y las artes, $\mathrm{n}^{\circ}$ 138, 2001 (Ejemplar dedicado a: La cartografía: infraestructura geográfica para la toma de decisiones), 103-136.

CAMARILLO NARANJO, J.M Y VALLEJO VILLALTA, I. (2000): La gestión de los riesgos naturales en el ámbito de la Protección Civil. Boletín de la Asociación de Geógrafos Españoles, no 30, 51-68.

CONESA GARCÍA, C. y ALVAREZ ROGEL, Y. (2003): «Propuesta metodológica para la delimitación de áreas inundables y la estimación de usos afectados en sistemas de drenaje efímero». Nimbus: Revista de Climatología, Meteorología y Paisaje, nº 11-12, 2003, 107-128.

CONESA GARCÍA, C. y GARCÍA LORENZO, R. (2007): Erosión y diques de retención en la Cuenca Mediterránea. Efectividad hidrogeomorfológica de los diques de retención en cuencas torrenciales del Sureste español. Murcia. Fundación Instituto Euromediterráneo del Agua.

DÍEZ HERRERO, A. y LAÍN HUERTA, L. (1998): «Aportaciones de los estudios realizados por el ITGE a la prevención del riesgo de inundaciones» en GÓMEZ ORTÍZ, et al. (Ed.) Investigaciones recientes de la geomorfología española. Barcelona, Universidad de Barcelona.

DÍEZ HERRERO, A. y PUJADAS FERRER, J. (2002): «Los mapas de riesgo de inundaciones», en Riesgos naturales (AYALA-CARCEDO, F.J.; OLCINA CANTOS, J. Coord.). Barcelona, Ariel Ciencia, 997-1012.

DÍEZ HERRERO, A; LAÍN HUERTA, L. y MIGUEL LLORENTE, I. (Eds.) (2006): Mapas de peligrosidad de avenidas e inundaciones: métodos, experiencias y aplicación. Instituto Geológico y Minero de España, 232 pp.

DIRECCIÓN GENERAL DE PROTECCIÓN CIVIL DE LA REGIÓN DE MURCIA (2007): Plan Especial de Protección Civil ante el riegos de inundaciones de la Comunidad Autónoma de la Región de Murcia (Plan INUNMUR). Murcia, soporte digital. 
ELÍZAGA, E.; GARAY, P. y GUTIÉRREZ, P. (1983): El mapa de Riesgos Geológicos como documentación preventiva ante la dinámica fluvial de la cuenca baja del río Júcar, en $2^{\mathrm{a}}$ Reunión Nacional de Geología Ambiental y Ordenación del Territorio, 7-23.

ETXEBERRÍA RAMÍREZ, P. (2004): Metodología para la creación de cartografía de peligros naturales en Gipuzkoa. Aplicación al valle de Oiartzun. Tesis doctoral dirigida por José Miguel Edeso Fito, Adolfo Brazaola Rojo. Universidad del País Vasco (2004).

GIMÉNEZ FONT, P. (2009): «Cauces meandriformes y riesgos naturales en la cartografía histórica del mediterráneo español». Mapping, $\mathrm{n}^{\circ}$ 133, 12-16.

MARTÍN ISABEL, M. P.; CHUVIECO SALINERO, E.; OLIVA PAVÓN, P.; RODRÍGUEZ VERDÚ, F.; NIETO SOLANA, H.; PADRÓN PAREDES, D. (2007): «Un ejemplo práctico de aplicación operativa de la teledetección a la gestión de riesgos naturales: cartografía y evaluación urgente de áreas quemadas en Galicia». Cuadernos de investigación geográfica, ISSN 0211-6820, n 33, 19-38.

OLCINA CANTOS, J. (2007): Riesgo de inundaciones y ordenación del territorio en España. Murcia. Fundación Instituto Euromediterráneo del Agua.

ORTEGA BECERRIL, J.A.; GARZÓN HEYDT, M.G.; GARCÍA LÓPEZ-DAVALILLO, J.C.; RODRIGUEZ FRANCO; A. (2009): Funcionamiento de la rambla de Nogalte (Murcia) durante avenidas. Implicaciones para la cartografía de peligrosidad por riesgo de avenidas en Avances en estudios sobre desertificación, Universidad de Murcia, $497-$ 500 .

PERNÍA, J.M.; DEL VAL, J.; DE SIMÓN, A.; BOQUERA, J.; ARTAÍZ, C.; (1987): Mapas previsores de riesgos de inundaciones en núcleos urbanos: Puerto Lumbreras, Lorca, Totana, Archena, en Serie Geología Ambiental, Madrid. IGME.

PUJADAS, J.; PAZ, A. de; MARTURIÁ J. y VELASCO, E. (1997): «Cartografía de riesgos por inundación». Tecnoambiente, 69, 54-59.

RIBERA MASGRAU, L. (2004): «Los mapas de riesgo de inundaciones: representación de la vulnerabilidad y aportación de las innovaciones tecnológicas». Anales de Geografía, $n^{\circ} 43,153-171$.

RICO AMORÓS, A.; OLCINA CANTOS, J. y GIL OLCINA, A. (Eds.) (2006): Aguaceros, aguaduchos e inundaciones en áreas urbanas alicantinas. Alicante. Universitat d' Alacant.

TRIVIÑO PÉREZ, A. y ORTIZ ROJAS, S. (2004): «Metodología para la modelación distribuida de la escorrentía superficial y la delimitación de zonas inundables en ramblas y ríos-rambla mediterráneos». Investigaciones Geográficas, nº 35, 67-84. 
